\title{
GMR
}

\section{RETRACTION of "Methylation of the RASSFIA promoter in breast cancer" by Y. Ji, H.H. Jin, M.D. Wang, W.X. Cao, J.L. Bao - Genet. Mol. Res. 15 (2): gmr.15028261 (2016) - DOI: 10.4238/gmr.15028261}

\author{
Genet. Mol. Res. 15 (4): gmr.150482611 \\ Published October 7, 2016 \\ DOI http://dx.doi.org/10.4238/gmr.150482611 \\ Copyright $(2016$ The Authors. This is an open-access article distributed under the terms of \\ the Creative Commons Attribution ShareAlike (CC BY-SA) 4.0 License.
}

The retracted article is:

Ji Y, Jin HH, Wang MD, Cao WX, et al. (2016). Methylation of the RASSFIA promoter in breast cancer. Genet. Mol. Res. 15: gmr.15028261.

There are significant parts of this article (particularly, in the discussion section) that are copied from "Methylation of HIN-1, RASSF1A, RIL and CDH13 in breast cancer is associated with clinical characteristics, but only RASSF1A methylation is associated with outcome", by Jia Xu, Priya B Shetty, Weiwei Feng, Carol Chenault, Robert C Bast Jr, JeanPierre J Issa, Susan G Hilsenbeck and Yinhua Yu, published in BMC Cancer 2012; 12: 243. DOI: $10.1186 / 1471-2407-12-243$.

The first paragraphs of both discussions are identical. This is concerning. The abstract and introduction sections have much of their text plagiarized. Overall, there is high plagiarism detected.

The GMR editorial staff was alerted and after a thorough investigation, we have strong reason to believe that the peer review process was failure and, after review and contacting the authors, the editors of Genetics and Molecular Research decided to retract the article in accordance with the recommendations of the Committee on Publication Ethics (COPE). The authors and their institutions were advised of this serious breach of ethics.

\section{Link to original paper}

Genetics and Molecular Research 15 (4): gmr.150482611 